\title{
Vigotski e os fundamentos de uma psicologia marxista
}

Paulo C. Duarte Paes ${ }^{1}$

Em toda a extensão da obra de Vigotski o materialismo histórico e dialético aparece como a referência teórica que fundamenta suas reflexões nos campos da psicologia e da pedagogia. Ele utiliza algumas vezes estes conceitos, associados à palavra psicologia, para identificar o referencial epistemológico dos seus estudos, tais como: psicologia dialética (La psique, la consciência, el inconsciente ${ }^{2}$ ), materialismo psicológico (El significado histórico da la crisis de la psicologia ${ }^{3}$ ), psicologia marxista e psicologia histórica ou histórico-social (El método instrumental em psicologia e A história do comportamento ${ }^{5}$ ). A associação destas categorias da teoria do conhecimento criada por Marx à palavra psicologia é feita com fins didáticos apenas para reforçar suas convicções metodológicas em alguns momentos, já que Vigotski não identifica a teoria que criou como um campo a mais da psicologia como: a psicologia social, a psicologia pedagógica ou a psicologia infantil. Ele afirma a necessidade da existência de uma única psicologia como ciência que denomina "psicologia geral" ou apenas "psicologia"6 e que abarca todas as outras especificidades da psicologia, como a Gestalt, a Psicanálise ou a Reflexologia. É

1. Doutorem Educação - UFSCar - pdpaes@yahoo.com.br

2. Levy S. Vygotski. Obras escogidas (Volume I). Madri, Publicaciones del M.E.C. / Visor, 1991, p. 99 - 102.

3. Vygotski. Obras escogidas. cit., p. 398 - 392.

4. Vygotski. Obras escogidas. cit., p.69

5. Levy S. Vygotsky. A história do comportamento: o macaco, o primitivo e a criança. Porto Alegre, Artes Médicas, 1996.

6. Vygotski. Obras escogidas. cit., p. 388 e 405.

Marxismo e educação

cadernos cemarx, $\left.\mathrm{n}^{0} 3-2006\right) 173$ 
elucidativa da posição de Vigotski a respeito desta questão a seguinte reflexão:

Um marxista historiador nunca dirá "história marxista da Rússia" considerando que isso se depreende do próprio fato. Marxista para ele é sinônimo de "verdade" de "científica", pois não reconhece outra história que não a marxista. E para nós a questão deve ser formulada da seguinte maneira: nossa ciência se converterá em marxista na medida em que se converta em verdadeira, científica, e é precisamente à sua transformação em verdadeira, e não à sua subordinação à teoria de Marx, que nós vamos nos dedicar. Tanto para preservar o legítimo significado da palavra quanto para responder a essência do problema não podemos afirmar: "psicologia marxista" no sentido que se diz: psicologia associativa, experimental, eidética. A psicologia marxista não é uma escola entre outras, mas a única psicologia verdadeira como ciência. Outra psicologia, além dela, não pode existir ${ }^{7}$.

A obra de Vigotski, desde suas primeiras publicações sobre psicologia da arte e psicologia pedagógica até os seus últimos trabalhos mais aprofundados sobre a psicologia do desenvolvimento como pensamento e linguagem, demonstra uma busca permanente de respostas para problemas concretos da sociedade soviética. Seu entendimento sobre a psicologia fundamentou-se cada vez mais no materialismo histórico e dialético, conforme seu trabalho se tornava mais complexo e aprofundado. Demonstraremos a seguir algumas categorias do pensamento marxiano que foram os pilares da obra vigotskiana e da psicologia sócio-histórica.

\section{Materialismo em Vigotski: fundamento de sua crítica aO "PSicologismo idealista"}

O autor identifica os aspectos metafísicos que levaram a psicologia tradicional a entender os fenômenos psíquicos separados dos demais fenômenos do mundo e a acreditar que esses são imateriais e inacessíveis à experiência objetiva ${ }^{8}$. Fazendo a crítica do que chama de "psicologismo", Vigotski nomeia várias vertentes da psicologia como

7. Vygotski. Obras escogidas, cit., p.404.

8. Vygotski. Obras escogidas, cit., p.405

9. Vygotski. Obras escogidas, cit., p. 116.

174 Vigotski e os fundamentos de uma psicologia marxista 
a Psicanálise e a Gestalt como psicologias idealistas, que estudam a psicologia como se a psique fosse algo "independente", sem relação com a base material e histórica da existência humana ${ }^{9}$. O cerne da crítica por ele proposta está na compreensão dos aspectos materiais e espirituais como partes inseparáveis, dialeticamente relacionadas e determinadas historicamente.

Admitindo assim, a existência de fenômenos imateriais, desprovidos de espaço, essa psicologia mantinha na íntegra a visão dualista da natureza humana própria do pensamento primitivo e religioso. Não é por acaso que essa psicologia estava estritamente ligada a filosofia idealista, que ensinava que o espírito é um princípio específico e diferente da matéria, enquanto a consciência tem uma realidade especial, autônoma, independente do ser. ${ }^{10}$

Vigotski identifica as bases idealistas da Psicanálise e da Gestalt como originárias em Hegel e Husserl, ao qual chama de "idealista extremo""1. Contrapondo-se ao idealismo, que vê na consciência humana a própria realidade, ele utiliza a concepção marxiana que afirma ser a matéria uma realidade objetiva que existe independentemente da consciência humana. Não é a consciência que determina a vida, mas sim a vida que determina a consciência ${ }^{12}$.

$\operatorname{Vigotski}^{13}$ (2001, p.8), afirma ainda que o primeiro traço da nova psicologia é o seu materialismo, uma vez que todo comportamento do homem como constituído de uma série de movimentos e reações é dotado de todas as propriedades da existência material. Para Vigotski os fenômenos psíquicos não podem partir de explicações idealistas que justificam as emoções, os sentimentos, a subjetividade e o subconsciente como algo em si mesmo, mas devem ser fundamentados no entendimento materialista de Marx. Para ele, essas manifestações possuem causas materiais e históricas:

A natureza dotou o homem de uma necessidade estética que possibilita que este tenha idéias, estéticas, gostos e sensações. Porém, estabelecer com exatidão que gostos, idéias e sensações terá o homem social em questão, em

10. Vygotski. Obras escogidas, cit., p.404

11. Vygotski. Obras escogidas, cit., p. 304, 341 e 342

12. Karl Marx e Friedrich Engels. A ideologia alemã (Feuerbach). São Paulo, Hucitec, 1982. p. 21.

13. Levy S.Vigotski. Psicologia Pedagógica. São Paulo, Martins Fontes, 2001b, p. 08.

Marxismo e educação

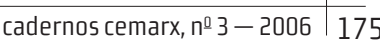


uma determinada época histórica, não é diretamente dedutível da natureza do

homem. Essa resposta só nos pode ser dada por uma interpretação materialista da história.$^{14}$

Seu entendimento materialista do desenvolvimento humano o levou a uma posição contrária ao idealismo predominante na psicologia ${ }^{15}$. Vigotski produziu uma extensa crítica ao excesso de importância dada ao inconsciente, "reduzindo a nada toda a consciência que, segundo a expressão de Marx, constitui a única diferença entre o homem e o animal"16. Para o autor, Freud associou sem a devida fundamentação o inconsciente ao desejo sexual, notadamente na fase infantil, como uma relação edipiana e negligenciou todo um complexo encadeamento de outros determinantes históricos, materiais e emocionais. "A psicanálise reduz todas as manifestações do psiquismo humano a mera atração sexual, adotando um pansexualismo infundado"17. Para Vigotski o inconsciente guarda especificidades que não podem ser entendidas de forma imediata, porque não foram entendidos através da linguagem como frustrações ocorridas no passado:

Tudo que Freud denomina inconsciente é, em essência, não verbal. (...) Não podemos recordar os acontecimentos mais antigos da infância precisamente porque se produziram quando nosso comportamento não estava ainda verbalizado e, por isso, a parte mais antiga da nossa vida será sempre inconsciente para nós. ${ }^{18}$

Para Vigotski tomar o inconsciente como objeto central da psicologia é fruto de uma concepção idealista que considera a psique uma esfera totalmente separada e sobre a qual não atuam as leis do mundo material, constituindo-se o verdadeiro "reino do espírito"19. Fundamentado na perspectiva monista formulada por Marx, Vigotski propõe uma compreensão do inconsciente que leve a uma ação concreta através

14. Vigotski, Psicologia Pedagógica, cit., p. 273.

15. Vigotski, Psicologia Pedagógica, cit., p. 402

16. Vigotski, Psicologia Pedagógica, cit., p. 93.

17. Levy S. Vigotski. Psicologia da arte. São Paulo, Martins Fontes, 2001a, p.92.

18. Vygotski. Obras escogidas, cit., p. 110.

19. Vygotski. Obras escogidas, cit., p. 112.

176 Vigotski e os fundamentos de uma psicologia marxista 
da educação do indivíduo inserido na realidade social e coletiva. Assim, Vigotski justifica a necessidade de transformar um reflexo agressivo de ordem inferior em uma ação concreta de ordem superior, criativa e socialmente conectada a interesses da classe revolucionária.

Vigotski (1991) denuncia, citando Marx, a ausência da perspectiva histórica na psicologia idealista e na psicologia comportamental, que compreendem a identidade humana separada de sua gênese histórica e, portanto, "fantasmagórica" e fruto de uma imaginação alienada que reproduz inconscientemente interesses materiais, da elite detentora do capital. Essa percepção histórica, contraria à naturalização das relações sociais, Vigotski fundamentou na obra marxiana. Segundo $\operatorname{Marx}^{20}$, a reificação das mercadorias impõe um falso valor às mesmas, com base nos interesses de mercado e não no valor equivalente ao trabalho despendido para sua confecção. As mercadorias passam então a ser compreendidas como um valor em si e não como resultado da atividade humana.

Para Marx somente é possível compreender a origem das relações sociais pela compreensão da evolução histórica da humanidade ao mesmo tempo em que o indivíduo humano somente o é, de fato, se for dotado de capacidade de desenvolver atividades sociais de transformação desta própria realidade histórica dada:

A história não é senão a sucessão das diferentes gerações, cada uma das quais explora os materiais, os capitais, as forças produtivas que lhe são transmitidas pelas gerações precedentes. Assim sendo, cada geração, por um lado, continua o modo de atividade que lhe é transmitido, mas em circunstâncias radicalmente transformadas, e, por outro lado, ela modifica as antigas circunstâncias entregando-se a uma atividade radicalmente diferente. ${ }^{21}$

Os interesses de mercado, a exacerbação do consumo pelos interesses de lucro da produção, a alienação da mercadoria em relação ao trabalho despendido na sua confecção são determinantes do desenvolvimento histórico da humanidade e da consciência do indivíduo. Essa realidade material, com seus interesses de classe, induz seus valores éticos, estéticos e lógicos ao restante das relações sociais, explicando, assim,

20. Karl Marx. O método da economia política. (Coleção Os Pensadores) São Paulo, Abril Cultural, 1989, p. 72. 21. Karl Marx e Friedrich Engels. A ideologia alemã (Feuerbach). São Paulo, Hucitec, 1982, p. 46.

Marxismo e educação

cadernos cemarx, n-3-2006 177 
porque filósofos e psicólogos reproduzem um pensamento idealista, biologicista ou fenomenológico, para explicarem a consciência humana. Assim, também as tendências da psicologia tradicional fundamentam-se em pressupostos teóricos produzidos sob a influência histórica dos interesses liberais.

Estudar algo historicamente significa estudá-lo em movimento. Essa é a exigência fundamental do método dialético. (...) Assim pois, a investigação histórica da conduta não é algo que complementa ou ajuda o estudo teórico, senão que constitui seu fundamento.$^{22}$

Para além da compreensão sobre os determinantes históricos da cultura humana, Vigotski aponta para o processo criativo do "fazer história", com o mesmo sentido dado por Marx ao termo. Ou seja, se por um lado a humanidade deve ser educada para se apropriar da realidade histórica, de forma a tomar consciência desse processo, por outro lado, é necessária a superação da sociedade de classes alicerçada no modo de produção capitalista, para a produção de uma nova ordem de relações mundiais. A velha psicologia que tem como objeto apenas o indivíduo, negligenciando a totalidade do gênero humano, não é ciência.

\section{O PRINCÍPIO DE TOTALIDADE NA OBRA VIGOTSKIANA}

Vigotski parte do pressuposto marxiano de que a sociedade, tendo em vista o seu caráter histórico, é uma totalidade em permanente inter-relação com infinitas particularidades. Para ele o desenvolvimento psicológico do indivíduo somente pode ser percebido na relação dialética entre a totalidade concreta das forças materiais no seu movimento histórico e os demais produtos do gênero humano. Ao compreender a consciência do indivíduo isoladamente a psicologia idealista reflete uma ideologia produzida historicamente que deve ser desvelada para ser efetivamente entendida como parte da totalidade histórica.

A categoria de totalidade, empregada do ponto de vista do pensamento materialista histórico, pressupõe a existência de uma forma superior de organicidade humana nas relações materiais que a tudo induz e se deixa induzir. O capitalismo enquanto tal

22. Levy S. Vigotski, Psicologia da arte. cit., p. 67 - 68.

178 Vigotski e os fundamentos de uma psicologia marxista 
foi produzido historicamente a partir da existência do dinheiro, do salário, do lucro, ainda dentro de um modelo fragmentado de relações econômicas no mundo Feudal e Antigo. O capital passa a ser a forma central de desenvolvimento da humanidade como um todo, uma totalidade concreta. "A totalidade concreta não é um método para captar e exaurir todos os aspectos, caracteres, propriedades, relações e processos da realidade; é a teoria da realidade como totalidade concreta"23.

Segundo Vigotski, para que se proporcione à criança relações ativas e criadoras não basta o ensino de habilidades, como lidar com máquinas, mas o fato de que a criança penetre no sentido de toda a produção para que descubra o significado de determinados procedimentos técnicos como partes indispensáveis de uma totalidade. O mesmo pode ser compreendido de um texto de Marx nos Grundisse, mas com o tema da economia política ao invés da psicologia pedagógica estudada por Vigotski: "Finalmente a produção também não é apenas uma produção particular, mas é sempre, ao contrário, certo corpo social, sujeito social, que exerce sua atividade numa totalidade maior ou menor de ramos da produção"24.

O isolamento da particularidade como explicação em si mesma é uma concepção fenomenológica denunciada por Marx e por Vigotski, pelo seu caráter irreal, metafísico e fundamentado no domínio do espírito sobre a realidade, tal qual a velha psicologia.

\section{A crítica de Vigotski ao eCLETISMO PSEUdo-CIENTífico}

Fundamentado na perspectiva da impossibilidade de compreensão da consciência humana utilizando apenas o fragmento contido na individualidade, Vigotski foi um crítico veemente das posições ecléticas que afirmam ser possível a junção de princípios metodológicos inconciliáveis. "Utilizar do parêntesis da metodologia geral de uma época e diluir nela o marxismo significa transformar não só a aparência, mas também a essência do marxismo"25.

Sua crítica parte da impossibilidade de comunhão entre os pressupostos teóricos de Freud, que fundamenta a psicologia na sexualidade e no inconsciente, com o materialismo de Marx que tem como pressuposto central a produção material da história pelo trabalho como determinante da consciência individual e

23. Karel Kosik. A Didalética do concreto. São Paulo, Associados, 1991. p. 44.

24. Karl Marx. 0 método da economia política. cit. p. 111.

25. Vygotski. Obras escogidas, cit., p. 298.

Marxismo e educação

cadernos cemarx, $\left.\mathrm{n}^{0} 3-2006\right) 179$ 
coletiva. "E o que fazem os ecléticos: respondem a pergunta feita pela psicologia marxista como o que lhes sugere a metapsicologia freudiana". Para Vigotski, o materialismo dialético exclui a possibilidade de somar mecanicamente os grandes feitos científicos, operando através da valorização de coincidências e não de fundamentos ${ }^{26}$. Ainda criticando autores que tentam identificar a psicanálise com o materialismo histórico, ele afirma que a psicanálise limita a psicologia, transformando a sexualidade em princípio metafísico de uma série de idéias metafísicas, transformando a psicologia em ideologia e em metapsicologia. "A anexação, a transposição mecânica de fragmentos de um sistema alheio a si próprio, parece produzir-se, neste caso como em todos os casos sempre, de maneira milagrosa e como evidência da verdade"27. Para Vigotski a valorização de "coincidências" como meio de se chegar a uma verdade científica através da junção de métodos completamente distintos apenas comprova a carência metodológica de princípios e o ecletismo de um sistema falho.

\section{Atividade humana}

Para os autores da psicologia sócio-histórica a atividade humana é o principal meio de transformação e produção da realidade social e da consciência. Aléxis Leontiev, um dos principais autores da Psicologia Sócio-Histórica e colaborador nas pesquisas de Vigotski, justifica a sua teoria da Psicologia da Atividade estudando os motivos, emoções e necessidades humanas. Nega os pressupostos idealistas da psicologia que naturalizam o sentido das emoções e por isso concebem "de ponta cabeça" a relação entre as necessidades humanas e as atividades humanas ${ }^{28}$. As concepções naturalizadoras da psicologia afirmam que as necessidades sempre se dão em primeiro lugar e geram as atividades. Leontiev parcialmente aceita que o indivíduo nasce com necessidades, mas afirma que essas necessidades, por serem históricas, vão se transformando na medida em que o sujeito realiza atividades.

A necessidade primeiramente se manifesta somente como uma condição, como uma premissa para a atividade, porém, tão logo o sujeito comece

26. Vygotski. Obras escogidas, cit., p. 274.

27. Vigotski, Psicologia da arte, cit., p. 296.

28. Aléxis Leontiev. O desenvolvimento do Psiquismo. Lisboa, Horizonte, 1978.

180 Vigotski e os fundamentos de uma psicologia marxista 
a atuar, imediatamente nela se opera uma transformação e a necessidade deixa de ser o que era virtualmente "em si". Quanto mais avança o desenvolvimento da atividade, mais sua premissa se transforma em seu resultado (LEONTIEV, 1983). ${ }^{29}$

As atividades humanas geram sempre novas necessidades a partir do seu desenvolvimento, tanto do ponto de vista da compreensão psicológica do indivíduo quanto do desenvolvimento histórico da sociedade. A produção material da história vai paulatinamente criando novas formas materiais e respectivas necessidades humanas conforme seus modelos de produção. As necessidades humanas se produzem como conseqüência das relações produtivas da sociedade, da práxis humana.

Leontiev $^{30}$ exemplifica que um homem numa situação de fome extrema tem a necessidade de alimento antecipada a qualquer forma de cultura alimentar produzida historicamente, porém, neste caso, o indivíduo se desumaniza. Como exemplifica Marx nos Grundisse (1974), o homem tem fome, mas não de comer carne crua dilacerada diretamente das vísceras de um animal. Sua fome obedece a padrões sociais e civilizados de alimentação.

Desde os primórdios o trabalho exigiu que a humanidade desenvolvesse certo grau de controle sobre seu próprio comportamento, na medida em que desenvolvesse também o controle sobre a natureza. O trabalho, como uma atividade humana exercida pelos indivíduos, é principal determinante da produção da consciência humana. Na concepção dos autores da psicologia sócio-histórica: "o trabalho criou o próprio homem"31.

\section{CONCLUSÃo}

Mesmo com a objetividade dos escritos de Vigotski, fundamentando a sua concepção de psicologia como ciência materialista, histórica e dialética, muitos são os autores que procuram equivocadamente difundir uma forma falsa do seu

29. Aléxis Leontiev. Actividad, consciência e personalidad. Havana, Pueblo edución. 1982. p. 156.

30. Aléxis Leontiev. O desenvolvimento do Psiquismo. Lisboa, Horizonte, 1978.

31. Friedrich Engels, Apud Vigotski. A História do comportamento, cit. p. 88 - 89.

Marxismo e educação

cadernos cemarx, nํ3-2006 181 
pensamento, associando-o a teorias fragmentadas de outros referenciais filosóficos, negando a essência da sua teoria. Seja por falta de conhecimento aprofundado sobre seu trabalho e seus pressupostos teóricos ou por motivos de mercado. Os autores que não têm domínio e conhecimento destas categorias reproduzem uma equivocada interpretação liberal da psicologia sócio-histórica, evitando o aspecto revolucionário do pensamento vigotskiano. "É necessária a ousadia revolucionária. Tudo o que restou como herança podre, da velha ordem, da moral burguesa, deve ser banido da escola" 32 .

32. Vigotski. Psicologia pedagógica. cit. P. 299.

182 Vigotski e os fundamentos de uma psicologia marxista 